\title{
Unrecorded Alcohol Consumption in Seven European Union Countries
}

\author{
Jakob Manthey ${ }^{a, b}$ Charlotte Probst ${ }^{c, d}$ Carolin Kilian ${ }^{a}$ Jacek Moskalewicz \\ Janusz Sierosławskie ${ }^{\text {Thomas Karlsson }}{ }^{f}$ Jürgen Rehm ${ }^{a-c, ~ g-j}$ \\ ${ }^{a}$ Institute of Clinical Psychology and Psychotherapy, Technische Universität Dresden, Dresden, Germany; ${ }^{b}$ Center \\ for Interdisciplinary Addiction Research, Department of Psychiatry and Psychotherapy, University Medical \\ Center Hamburg-Eppendorf, Hamburg, Germany; ${ }^{\mathrm{C} C e n t r e ~ f o r ~ A d d i c t i o n ~ a n d ~ M e n t a l ~ H e a l t h ~(C A M H), ~ I n s t i t u t e ~ f o r ~}$ \\ Mental Health Policy Research, Toronto, ON, Canada; ${ }^{d}$ Heidelberg Institute of Global Health, Universitätsklinikum

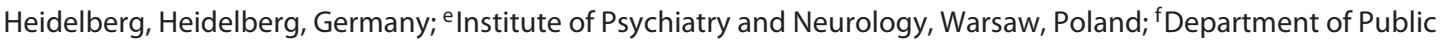 \\ Health Solutions, Finnish Institute for Health and Welfare (THL), Helsinki, Finland; ${ }^{9}$ Dalla Lana School of Public

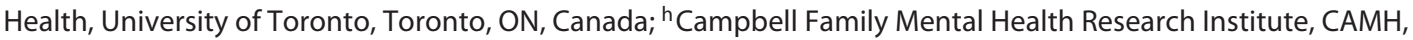 \\ Toronto, ON, Canada; 'Institute of Medical Science, University of Toronto, Toronto, ON, Canada; 'Department of \\ International Health Projects, Institute for Leadership and Health Management, I.M. Sechenov First Moscow State \\ Medical University, Moscow, Russian Federation
}

\section{Keywords}

Alcohol use · Unrecorded alcohol · Economic crisis · Spirits . Wine $\cdot$ Beer

\begin{abstract}
Introduction: Unrecorded alcohol, that is, alcohol not reflected in official statistics of the country where it is consumed, contributes markedly to overall consumption of alcohol. However, empirical data on unrecorded alcohol consumption are scarce, especially in high-income countries. This study measures the contribution of unrecorded alcohol in 7 member states of the European Union. Methods: Two categories of unrecorded consumption were assessed in general population surveys (reducing alcohol related harm Standardized European Alcohol Survey; $n=11,224$ ): homemade alcohol and cross-border shopping. Country-specific logistic regressions were used to link respondent characteristics to odds of acquisition of unrecorded alcohol. Total per capita alcohol consumption was estimated under different assumptions of calculating unrecorded alcohol consumption. Results: Individuals with higher drinking levels were
\end{abstract}

karger@karger.com www.karger.com/ear

Karger $\stackrel{\text { ' }}{5}$

BOPEN ACCESS
(C) 2020 The Author(s)

Published by S. Karger AG, Basel

This article is licensed under the Creative Commons AttributionNonCommercial-NoDerivatives 4.0 International License (CC BYNC-ND) (http://www.karger.com/Services/OpenAccessLicense). Usage and distribution for commercial purposes as well as any distribution of modified material requires written permission. more likely to acquire unrecorded alcohol in all 7 countries. In some countries, male sex and more affluent social class were also positively linked to acquisition of unrecorded alcohol. There was a substantial contribution of unrecorded alcohol to overall consumption in 5 out of 7 member states (Croatia, Finland, Greece, Hungary, Portugal), but not in Poland or Spain. In Greece, up to two-thirds of all alcohol consumed was estimated to be unrecorded. Conclusion: Unrecorded alcohol contributes to overall consumption even in high-income countries, and thus needs to be monitored. In monitoring, as many categories of unrecorded alcohol as possible should be clearly defined (e.g., surrogate alcohol) and included in future surveys. $\quad$ (2020 The Author(s)

Published by S. Karger AG, Basel

\section{Introduction}

Alcohol consumption is a substantial contributor to disease burden [1] and also poses a considerable economic strain to societies [2]. Total alcohol consumption - the
Jakob Manthey

Institute of Clinical Psychology and Psychotherapy

Technische Universität Dresden

Chemnitzer Strasse 46, DE-01187 Dresden (Germany)

E-Mail jakob.manthey@tu-dresden.de 
main indicator to estimate the disease and economic burden - is often assessed using taxation or import/export statistics only (see e.g., OECD [3]). While these sources do shed light on the level of recorded alcohol consumption, respective figures remain underestimates of the true consumption, as they do not capture the extent to which unrecorded alcohol is being consumed [4]. The term unrecorded alcohol refers to either licit (e.g., home-made beverages; alcohol officially manufactured for medical purposes) or illicit (e.g., illegally produced alcohol; for more details, see [5]) beverages and, in 2017, unrecorded alcohol, made up about $25 \%$ of global alcohol consumption [6]. Neither the research nor the clinical community has given sufficient attention to unrecorded alcohol use so far, which remains a topic predominantly discussed in alcohol policy contexts (for a recent example, see [7]). Raised awareness of unrecorded alcohol consumption may contribute to a more comprehensiveassessment of alcohol consumption among people with alcohol problems in clinical care.

There is clearly a gradient of unrecorded alcohol consumption with wealth: it is most prevalent in low- and lower-middle-income countries, and least prevalent in high-income countries (e.g., $[1,8])$. However, while this finding seems to be consistently reported, empirical evidence for it is lacking [9], and most overviews are based on expert judgments [10]. In particular, most of the empirical evidence in the form of surveys comes from middle and low-income countries, as part of the STEP-wise survey program of the World Health Organization (WHO) [11]. STEP-wise surveys focus on low- and middle-income countries which lack their own national surveys on risk factors for non-communicable disease [12]. For high-income countries, with very few exceptions such as Estonia, Finland, and Sweden [13-15] where unrecorded alcohol use is monitored regularly, questions about unrecorded alcohol are missing in general health or specialized alcohol surveys. However, outdated estimates, such as the data from the European Comparative Alcohol Study [16], seem to persist in reporting unrecorded alcohol consumption in the European Union (EU).

The Standardized European Alcohol Survey (SEAS), which was implemented as part of the European "Reducing Alcohol Related Harm" (RARHA) project in 2015, provides the most recent data on unrecorded consumption in the EU [17]. Out of 19 countries participating in the RARHA SEAS, 7 countries (Croatia, Finland, Greece, Hungary, Poland, Portugal, and Spain) included questions about unrecorded alcohol in their survey versions. As described in the Synthesis report [17], on average one in 5 respondents from the 7 countries confirmed acquisi- tion of alcohol from unrecorded sources, with varying proportions in individual countries (from $4 \%$ percent in Spain to $40 \%$ in Greece and Finland). The survey results also indicated that there were large differences between countries with respect to sourcing unrecorded alcohol (mainly foreign sources in Finland, mainly domestic sources in Greece, Croatia, and Portugal) and with regard to beverage type (predominately wine in Croatia, Greece, Hungary, Portugal, and Spain; predominately spirits in Finland and Poland). With regard to the per capita proportion of unrecorded consumption in recorded consumption, the estimates ranged widely, from below $5 \%$ (Hungary, Poland, Spain), to 10-25\% (Croatia, Finland, Portugal) and up to $>50 \%$ (Greece).

This paper extends the analyses presented in the Synthesis report in 2 parts. In the first part, we examine characteristics of people acquiring unrecorded alcohol in each country. We hypothesized that acquisition of unrecorded alcohol would be most prevalent in the economically disadvantaged (due to higher affordability), and in groups with the highest consumption volumes (i.e., among people with heavier alcohol consumption and among males). In the second part, we estimated the absolute liters of unrecorded consumption as well as the proportion of unrecorded consumption of total per capita consumption using country-validated data from the WHO. For the latter, different assumptions related to calculating levels of unrecorded alcohol consumption are discussed and applied.

\section{Materials and Methods}

Survey Design, Implementation and Assessment of Alcohol Consumption

The unrecorded section was implemented in 7 EU countries participating in RARHA SEAS. In all countries, randomised sampling procedures were applied to select a representative general population sample aged 18-64 years. In each country, between 1,500 and 2,000 people were interviewed (total $n=11,224$; for sample size by country see Table 3 ). Responses were obtained via computer-assisted telephone interviews (Finland and Greece) or computer-assisted personal interviews (Croatia, Hungary, Poland, Portugal, and Spain).

To assess past-year individual consumption levels, respondents provided data on their usual intake of beer, wine, and spirits using a beverage-specific quantity frequency (BSQF) approach. In addition, questions on frequency of risky single-occasion drinking (RSOD) were asked using a threshold of $40 \mathrm{~g}$ of pure alcohol for women and $60 \mathrm{~g}$ for men. Both measures were combined to estimate annual consumption of pure alcohol (ethanol) using the alcohol-by-volume values reported by individual countries (beer - 5\%; wine $-12 \%$; spirits $-40 \%$ ). To avoid overestimation of individual 
Table 1. Methods to calculate the population level of unrecorded alcohol consumption

\begin{tabular}{ll}
\hline Method & Details \\
\hline Absolute & Survey-derived absolute levels of unrecorded consumption aggregated across all survey respondents \\
\hline Relative & $\begin{array}{l}\text { Survey-derived relative levels of unrecorded consumption, that is, proportion of unrecorded among total consumption } \\
\text { levels, aggregated across all survey respondents and combined with recorded alcohol statistics to derive absolute levels }\end{array}$
\end{tabular}

consumption, capping procedures were applied at a level of $400 \mathrm{~g}$ of pure alcohol for daily alcohol intake of any alcoholic beverage, equaling about $183 \mathrm{~L}$ of pure alcohol for annual consumption.

\section{Assessment of Unrecorded Alcohol Consumption}

In this study, we use the term "unrecorded" to refer to alcohol acquired from either foreign or domestic sources, as long as it was untaxed in the country where it was brought to/acquired from (legal or illegal). On the contrary, the term "consumption" refers to the annual volume of alcohol reported to have been drunk by the respondents using BSQF measures, correcting for larger quantities consumed on single occasions (RSOD).

While each of the 7 countries adapted the questions to the local context for beverage type and for the most relevant categories of unrecorded alcohol, all countries arrived at beverage-specific estimates of the volume of home-made production and/or imported alcohol for the past 12 months, again in liters of pure alcohol per capita. English translations of the questions posed in each country can be found in the online supplementary Material (for all online suppl. material, see www.karger.com/doi/10.1159/000506333; original versions can be made available upon request). In Greece, the assessment of unrecorded alcohol consumption was limited to home-made liquor (ouzo or tsipouro) and wine only, as the proportion of home-made beer and imported alcohol was considered to be negligible. As a conservative estimate, we assumed no imported or home-made beer for Greece.

All questions referred to purchases or to other means of acquisition of unrecorded alcohol; in Hungary, respondents were additionally asked how much of the acquired unrecorded alcohol they consumed themselves. At the individual level, it was therefore possible that respondents could report having acquired a larger volume of unrecorded alcohol than the total amount of alcohol they had personally consumed in the past year. Therefore, RARHA SEAS did not allow us to estimate the individual level of unrecorded consumption but provided valuable data to estimate the population level of unrecorded consumption and its proportion of total alcohol consumption.

Part 1: Who Reports the Acquisition of Unrecorded Alcohol? (Individual Level Analyses)

At the individual level, we examined associations between sociodemographic variables and the acquisition of any unrecorded alcohol. In the first step, plots and crude associations were examined for sex (female vs. male), age, annual drinking volume, and social class. The latter was operationalized with current or most recent (for those previously employed) occupation: blue collar worker (skilled and unskilled manual worker), white collar worker (office worker), manager and professionals (supervisors and professionals with managerial position such as doctors, lawyers, etc.), and business person (business proprietor). For those who never worked, the occupation of a spouse or head of the primary family was coded in order to maintain the classification of social class for all respondents. In the second step, adjusted associations were determined by including all variables in one multivariate logistic regression model. In sensitivity analyses, we performed quasi-Poisson regressions with the same covariates but entered the total volume of unrecorded alcohol as the dependent variable.

\section{Part 2: Contribution of Unrecorded Alcohol to Total}

Consumption (Population-Level Analyses)

To start with, we contrasted the survey-derived average volume of annual alcohol consumption and unrecorded alcohol acquisition by beverage type. Next, we aimed to quantify the contribution of unrecorded alcohol to overall consumption. This required some considerations, which are discussed in the following.

In estimating the population level of unrecorded consumption from survey data, 2 different methods are possible and summarized in Table 1.

In contrast to absolute consumption levels, using the relative proportion of unrecorded alcohol does not assume that surveys accurately capture absolute levels of consumption. Given the substantial underestimation of surveys $[18,19]$, the second method seems more appropriate in calculating unrecorded consumption at the population level. However, it should also be noted that the "relative method" is built on the assumption that SEAS estimates of recorded and unrecorded consumption underestimate real consumption to the same degree in each individual country. Due to the assessment of unrecorded alcohol in RARHA SEAS, 2 additional assumptions were necessary:

1. The reported volume of unrecorded alcohol acquired reflected the volume of unrecorded alcohol consumed by the population in the past 12 months;

2. At the population level, $50 \%$ of the total volume of unrecorded alcohol acquired was included in the consumption section (assessed using BSQF and RSOD measures). While 50\% might seem like an arbitrary figure, it overlaps with the proportion reported by Hungarian respondents when asked how much of the acquired unrecorded alcohol they had consumed themselves (data not shown). Based on the assumption that the consumption measures (BSQF, RSOD) have captured $50 \%$ of the unrecorded alcohol volume, estimates for recorded consumption volume were corrected by deducting $50 \%$ of the unrecorded alcohol volume.

Finally, we calculated 3 total per capita alcohol consumption estimates: (1) wholly survey-based estimate under the above-described assumption that $50 \%$ of unrecorded alcohol use is already covered in the consumption section. For (2) and (3), we combined survey-based estimates of unrecorded consumption with recorded 
Table 2. Results from logistic regression on acquisition of any unrecorded alcohol

\begin{tabular}{|c|c|c|c|c|c|c|c|c|c|c|c|c|c|c|}
\hline \multirow[t]{2}{*}{ Predictors } & \multicolumn{2}{|c|}{ Croatia } & \multicolumn{2}{|c|}{ Finland } & \multicolumn{2}{|c|}{ Greece } & \multicolumn{2}{|c|}{ Hungary } & \multicolumn{2}{|c|}{ Poland } & \multicolumn{2}{|c|}{ Portugal } & \multicolumn{2}{|l|}{ Spain } \\
\hline & OR & $\mathrm{CI}$ & OR & $\mathrm{CI}$ & OR & $\mathrm{CI}$ & OR & $\mathrm{CI}$ & OR & $\mathrm{CI}$ & OR & $\mathrm{CI}$ & OR & CI \\
\hline Intercept & 0.23 & $0.15-0.36$ & 0.91 & $0.63-1.33$ & 0.55 & $0.36-0.83$ & 0.07 & $0.04-0.12$ & 0.09 & $0.05-0.17$ & 0.10 & $0.05-0.19$ & 0.02 & $0.01-0.05$ \\
\hline Gender, female & 0.74 & $0.57-0.94$ & 0.70 & $0.56-0.87$ & 1.13 & $0.91-1.41$ & 0.50 & $0.36-0.69$ & 1.00 & $0.69-1.44$ & 0.96 & $0.67-1.39$ & 1.30 & $0.77-2.18$ \\
\hline Age, years & 1.01 & $1.01-1.02$ & 0.99 & $0.98-1.00$ & 1.00 & $0.99-1.01$ & 1.01 & $1.00-1.03$ & 0.99 & $0.98-1.00$ & 1.00 & $0.99-1.01$ & 1.00 & $0.98-1.02$ \\
\hline Annual alcohol consumption & 1.01 & $1.00-1.02$ & 1.04 & $1.02-1.05$ & 1.02 & $1.00-1.03$ & 1.02 & $1.01-1.03$ & 1.04 & $1.03-1.05$ & 1.04 & $1.03-1.05$ & 1.05 & $1.03-1.06$ \\
\hline Social class: business person & 0.75 & $0.41-1.35$ & 1.11 & $0.73-1.70$ & 1.18 & $0.81-1.72$ & 2.07 & $1.15-3.73$ & 3.84 & $1.95-7.55$ & 0.99 & $0.49-2.02$ & 1.69 & $0.74-3.87$ \\
\hline $\begin{array}{l}\text { Social class: manager and } \\
\text { professionals }\end{array}$ & 0.98 & $0.69-1.39$ & 1.68 & $1.29-2.18$ & 1.07 & $0.78-1.47$ & 2.40 & $1.67-3.46$ & 3.34 & $2.11-5.29$ & 1.48 & $0.97-2.26$ & 2.23 & $1.25-3.97$ \\
\hline \multicolumn{15}{|l|}{ Social class: white collar } \\
\hline worker & 1.27 & $0.90-1.80$ & 1.32 & $0.98-1.78$ & 0.93 & $0.71-1.21$ & 1.34 & $0.86-2.10$ & 1.78 & $1.15-2.75$ & 0.66 & $0.38-1.16$ & 1.43 & $0.63-3.28$ \\
\hline Social class: other & 1.18 & $0.74-1.90$ & NA & NA & 1.44 & $0.35-5.91$ & 0.63 & $0.16-2.52$ & 1.04 & $0.24-4.59$ & NA & NA & NA & NA \\
\hline Observations & & 1,425 & & 1,469 & & 1,471 & & 1,883 & & 1,510 & & 1,464 & & 1,564 \\
\hline
\end{tabular}

For social class, blue collar workers were used as reference category. Bold denotes significant at level of $p=0.05$

NA, no respondents were classified as "other" social class in Finland, Portugal, and Spain.

per capita consumption data from the WHO from the same year [6]. Recorded consumption is considered to be the least biased estimate of alcohol consumption, and the WHO based its assessment on a hierarchy of considerations, where the highest credence was given to government estimates based on alcohol taxation revenues [20]. For (2), the absolute estimate of unrecorded alcohol volume from SEAS was added to the recorded volume (see Table $1-\mathrm{Ab}$ solute). For (3), the proportion of unrecorded alcohol calculated from SEAS was applied to recorded alcohol in order to calculate the total alcohol per capita consumption (see Table 1 - Relative).

In sensitivity analyses, we changed one of the assumptions that $50 \%$ of the unrecorded alcohol was covered in the consumption section at the population level. In these analyses, we assumed that none of the unrecorded alcohol was already covered in the consumption section, thus recorded consumption was not corrected as in the main analysis above. Consequently, the total per capi$t a$ alcohol consumption was simply calculated from the sum of the consumption section (i.e., recorded volume, as obtained through $\mathrm{BSQF}$ and RSOD) plus the unrecorded alcohol volumes. These data are reported in the online supplementary Material, which also contains results from the additional calculations using WHO data on recorded alcohol volumes, in which the absolute or proportional estimates of unrecorded volume were applied to arrive at total per capita consumption.

All analyses were performed with R version 3.5.1 [21] and survey weights were used in all analyses of individual data to account for sample selection bias.

\section{Results}

Overall, 2,236 respondents reported the acquisition of any amount of unrecorded alcohol (range $4 \%$ in Spain to $41 \%$ in Finland). In $7 \%$ of respondents, the volume of unrecorded alcohol exceeded the volume of their reported personal alcohol consumption (below 5\% in Hungary, Poland, Portugal and Spain; Finland: 9\%, Croatia: 11\%, Greece: 21\%).

Unrecorded Alcohol in Seven EU Countries

\section{Part 1: Who Reports the Acquisition of Unrecorded} Alcohol?

In the online supplementary Material, acquisition of any amount of unrecorded alcohol and mean volume of acquired unrecorded alcohol is illustrated for each country, by sex, age, drinking level, as well as social class (online suppl. Fig. 1-3).

The country-specific results of the adjusted associations are reported in Table 2. The most consistent predictor of the acquisition of any amount of unrecorded alcohol was annual consumption of alcohol, with higher consumption associated with a higher likelihood of acquisition of unrecorded alcohol (significant in all countries). Further, males and older people were more likely to acquire unrecorded alcohol in Croatia, Finland, and Hungary, but not in the remaining countries. Lastly, managers, professionals, and/or business people were more likely to report the acquisition of unrecorded alcohol than blue collar workers in Finland, Hungary, Poland, and Spain (Table 2).

In sensitivity analyses, we found similar but less consistent associations with the overall volume of unrecorded alcohol acquired. Annual alcohol consumption was positively associated with the volume of alcohol acquired in 6 out of 7 countries. While the average volume of unrecorded alcohol was larger among males in Finland and Hungary, it was significantly lower in Poland. A positive age gradient was identified in Croatia, Hungary, and Poland. Lastly, higher volumes of unrecorded alcohol were acquired by business people and/or managers or professionals compared to blue collar workers in Greece, Poland, and Spain (online suppl. Table 1 for detailed results). 
Table 3. Survey-derived average volume of annual alcohol consumption and unrecorded alcohol acquisition in liters per capita pure alcohol by country and beverage type

\begin{tabular}{|c|c|c|c|c|c|c|c|}
\hline & Number & $\begin{array}{l}\text { Year of } \\
\text { field-work }\end{array}$ & & Total & Beer & Wine & Spirits \\
\hline \multirow[t]{3}{*}{ Croatia } & 1,476 & 2015 & Consumption in l pure alcohol & $6.0(5.3-6.8)$ & $3.5(3.0-4.0)$ & $2.0(1.6-2.4)$ & $0.6(0.4-0.8)$ \\
\hline & & & Unrecorded in l pure alcohol & $1.3(1.0-1.7)$ & $0.1(0.1-0.2)$ & $0.7(0.5-1.0)$ & $0.5(0.2-0.7)$ \\
\hline & & & Unrecorded from cross-border shopping, \% & $12.3(8.7-16.0)$ & $52.9(32.8-73.1)$ & $2.9(1.7-4.1)$ & $15.1(10.4-19.9)$ \\
\hline \multirow[t]{3}{*}{ Finland } & 1,494 & 2015 & Consumption in l pure alcohol & $4.8(4.3-5.3)$ & $2.5(2.1-2.8)$ & $0.9(0.8-1.0)$ & $0.8(0.6-1.0)$ \\
\hline & & & Unrecorded in l pure alcohol & $1.2(1.0-1.5)$ & $0.5(0.3-0.6)$ & $0.3(0.2-0.4)$ & $0.5(0.4-0.6)$ \\
\hline & & & Unrecorded from cross-border shopping, \% & $93.1(74.3-100.0)$ & $99.5(73.6-100.0)$ & $80.3(50.8-100.0)$ & $98.7(75.9-100.0)$ \\
\hline \multirow[t]{3}{*}{ Greece* } & 1,519 & 2015 & Consumption in l pure alcohol & $4.1(3.6-4.5)$ & $1.2(1.0-1.4)$ & $1.7(1.5-1.9)$ & $0.4(0.3-0.5)$ \\
\hline & & & Unrecorded in l pure alcohol & $4.0(3.2-4.9)$ & 0 & $2.8(2.1-3.4)$ & $1.6(1.1-2.1)$ \\
\hline & & & Unrecorded from cross-border shopping, \% & 0 & 0 & 0 & 0 \\
\hline \multirow[t]{3}{*}{ Hungary } & 1,995 & 2015 & Consumption in 1 pure alcohol & $4.2(3.7-4.6)$ & $2.2(2.0-2.4)$ & $1.4(1.1-1.7)$ & $0.5(0.4-0.6)$ \\
\hline & & & Unrecorded in l pure alcohol & $0.5(0.3-0.6)$ & $0.0(0.0-0.0)$ & $0.3(0.2-0.4)$ & $0.1(0.1-0.2)$ \\
\hline & & & Unrecorded from cross-border shopping, \% & $8.7(6.2-11.3)$ & $91.1(27.5-100.0)$ & $2.4(1.5-3.2)$ & $15.4(10.9-19.9)$ \\
\hline \multirow[t]{3}{*}{ Poland } & 1,537 & 2015 & Consumption in l pure alcohol & $6.0(5.4-6.6)$ & $3.5(3.2-3.9)$ & $0.5(0.4-0.7)$ & $1.5(1.3-1.7)$ \\
\hline & & & Unrecorded in l pure alcohol & $0.2(0.0-0.3)$ & $0.0(0.0-0.0)$ & $0.0(0.0-0.0)$ & $0.1(0.0-0.3)$ \\
\hline & & & Unrecorded from cross-border shopping, \% & $34.6(25.2-44.0)$ & $78.5(42.7-114.3)$ & $68.2(47.3-89.2)$ & $26.3(18.1-34.5)$ \\
\hline \multirow[t]{3}{*}{ Portugal } & 1,489 & 2015 & Consumption in l pure alcohol & $4.4(3.9-4.9)$ & $2.1(1.8-2.4)$ & $2.0(1.7-2.2)$ & $0.4(0.3-0.5)$ \\
\hline & & & Unrecorded in pure alcohol & $2.3(1.4-3.2)$ & $0.0(0.0-0.0)$ & $2.1(1.2-3.1)$ & $0.1(0.0-0.2)$ \\
\hline & & & Unrecorded from cross-border shopping, \% & $0.4(0.2-0.7)$ & $56.0(8.9-100.0)$ & $0.1(0.0-0.1)$ & $5.4(2.0-8.9)$ \\
\hline \multirow[t]{3}{*}{ Spain } & 1,636 & 2015 & Consumption in l pure alcohol & $5.7(5.3-6.2)$ & $3.1(2.7-3.4)$ & $1.2(1.1-1.4)$ & $1.5(1.3-1.6)$ \\
\hline & & & Unrecorded in l pure alcohol & $0.1(0.0-0.1)$ & $0.0(0.0-0.0)$ & $0.0(0.0-0.1)$ & $0.0(0.0-0.1)$ \\
\hline & & & Unrecorded from cross-border shopping, \% & $24.3(13.4-35.2)$ & $78.4(19.5-100.0)$ & $4.9(1.5-8.3)$ & $44.5(22.6-66.5)$ \\
\hline
\end{tabular}

* In Greece, unrecorded alcohol acquisition was assessed only for homemade wine and spirits. Thus, unrecorded beer and unrecorded alcohol from cross-border shopping was not assessed in this survey for Greece.

\section{Part 2: Contribution of Unrecorded Alcohol to Total} Consumption

In Table 3, the survey-derived annual liters of recorded alcohol consumed per capita are contrasted to the annual liters of unrecorded alcohol acquired per capita.

In Hungary, Poland, and Spain, absolute unrecorded levels between 0.1 and $0.5 \mathrm{~L}$ of pure alcohol per capita were reported. In Croatia, Finland, and Portugal, unrecorded alcohol volumes were generally higher, and ranged between 1.2 and $2.3 \mathrm{~L}$ per capita. The highest absolute volumes of unrecorded alcohol were reported in Greece, where unrecorded alcohol levels roughly equaled overall consumption volumes.

Overall, acquisition of unrecorded beer made up the smallest volume acquired from unrecorded sources. In Croatia, Greece, Hungary, and Portugal, acquisition of unrecorded wine made up the largest proportion of unrecorded alcohol and even exceeded consumption levels in Greece (2.8 vs. 1.7 L per capita). Volumes of unrecorded spirits were generally low except for Greece, where the acquisition of home-made spirits more than tripled the consumption of spirits. Relative to reported consumption volumes, acquisition of unrecorded spirits also played a considerable role in Croatia, Finland, and Portugal.

Table 4 gives an overview of the alcohol consumption indicators based on the assumption that $50 \%$ of the unrecorded alcohol was already reported by the respondents in the consumption measures. The table presents 3 different total per capita alcohol consumption estimates as calculated by (1) combining the survey-based estimates of recorded and unrecorded alcohol, (2) adding the absolute volume of unrecorded alcohol from SEAS (as reported in Table 3; absolute method) to WHO estimates of recorded consumption, and (3) calculating unrecorded alcohol from the proportion of unrecorded from SEAS and then adding it to WHO estimates of recorded consumption (relative method).

For all countries studied, the survey-derived estimates of recorded consumption were well below the estimates using WHO data on recorded consumption. Considering only the 2 latter estimates based on WHO data of recorded consumption, the results suggest that the 2 scenarios lead to different estimates for total alcohol consumed, especially for countries with substantial proportions of unrecorded alcohol. The total per capita consumption for 
Table 4. Total, recorded and unrecorded per capita alcohol consumption in liters pure alcohol per capita, as calculated from SEAS survey and taken from WHO estimates [1]

\begin{tabular}{|c|c|c|c|c|}
\hline Country & & Total & Recorded & $\begin{array}{l}\text { Unrecorded } \\
\text { (\% of total) }\end{array}$ \\
\hline Croatia & $\begin{array}{l}\text { SEAS }^{1} \\
\text { Absolute } \\
\text { Relative }\end{array}$ & $\begin{array}{r}6.7 \\
11.6 \\
12.8\end{array}$ & $\begin{array}{r}5.4 \\
10.3 \\
10.3\end{array}$ & $\begin{array}{l}1.3(19.6) \\
1.3(11.3) \\
2.5(19.6)\end{array}$ \\
\hline Finland & $\begin{array}{l}\text { SEAS }^{1} \\
\text { Absolute } \\
\text { Relative }\end{array}$ & $\begin{array}{r}5.4 \\
9.8 \\
11.1\end{array}$ & $\begin{array}{l}4.2 \\
8.6 \\
8.6\end{array}$ & $\begin{array}{l}1.2(23.0) \\
1.2(12.7) \\
2.6(23.0)\end{array}$ \\
\hline Greece & $\begin{array}{l}\text { SEAS }^{1} \\
\text { Absolute } \\
\text { Relative }\end{array}$ & $\begin{array}{r}6.1 \\
10.8 \\
19.9\end{array}$ & $\begin{array}{l}2.1 \\
6.7 \\
6.7\end{array}$ & $\begin{array}{r}4.0(66.3) \\
4.0(37.5) \\
13.2(66.3)\end{array}$ \\
\hline Hungary & $\begin{array}{l}\text { SEAS }^{1} \\
\text { Absolute } \\
\text { Relative }\end{array}$ & $\begin{array}{r}4.4 \\
11.3 \\
12.1\end{array}$ & $\begin{array}{r}3.9 \\
10.9 \\
10.9\end{array}$ & $\begin{array}{l}0.5(10.4) \\
0.5(4.0) \\
1.3(10.4)\end{array}$ \\
\hline Poland & $\begin{array}{l}\text { SEAS }^{1} \\
\text { Absolute } \\
\text { Relative }\end{array}$ & $\begin{array}{r}6.1 \\
10.6 \\
10.8\end{array}$ & $\begin{array}{r}6.0 \\
10.5 \\
10.5\end{array}$ & $\begin{array}{l}0.2(2.8) \\
0.2(1.6) \\
0.3(2.8)\end{array}$ \\
\hline Portugal & $\begin{array}{l}\text { SEAS }^{1} \\
\text { Absolute } \\
\text { Relative }\end{array}$ & $\begin{array}{r}5.6 \\
12.8 \\
17.8\end{array}$ & $\begin{array}{r}3.3 \\
10.5 \\
10.5\end{array}$ & $\begin{array}{l}2.3(41.0) \\
2.3(17.9) \\
7.3(41.0)\end{array}$ \\
\hline Spain & $\begin{array}{l}\text { SEAS }^{1} \\
\text { Absolute } \\
\text { Relative }\end{array}$ & $\begin{array}{l}5.8 \\
8.6 \\
8.6\end{array}$ & $\begin{array}{l}5.7 \\
8.5 \\
8.5\end{array}$ & $\begin{array}{l}0.1(1.5) \\
0.1(1.0) \\
0.1(1.5)\end{array}$ \\
\hline
\end{tabular}

${ }^{1}$ Estimates from SEAS, assuming that $50 \%$ of volume of acquired unrecorded alcohol was already included in the quantity reported as consumed. Hence, recorded consumption reported in SEAS was corrected by deducting $50 \%$ of population-level unrecorded volume.

The actual recorded consumption data from the WHO was used [1] and either the absolute or proportional value of unrecorded from SEAS was put into relation to these data.

SEAS, Standardized European Alcohol Survey; WHO, World Health Organization.

Greece would be $10.8 \mathrm{~L}$ per capita pure alcohol if the absolute value of unrecorded alcohol was used, compared to 19.9 L per capita pure alcohol using the relative method. For Portugal, the respective numbers would be 12.8 or $17.8 \mathrm{~L}$ pure alcohol per capita consumption.

In sensitivity analyses, the same calculations of total per capita alcohol consumption at the population level were repeated with the assumption that none of the unrecorded alcohol acquisition was already reported in the consumption section. Under this assumption, recorded alcohol volumes would not be corrected, resulting in lower proportions of unrecorded alcohol of total per cap-

Unrecorded Alcohol in Seven EU Countries ita alcohol consumption (results presented in online suppl. Table 2). As compared to the estimates presented in Table 3 (main analyses), the total per capita alcohol consumption would be lower in countries with a substantial contribution of unrecorded alcohol, namely, Greece (13.4 instead of 19.9 L) and Portugal (15.9 instead of $17.8 \mathrm{~L})$.

\section{Discussion/Conclusion}

At the individual level, the acquisition of unrecorded alcohol was found to be closely related to alcohol volume consumed. In several countries, acquisition of unrecorded alcohol has further been linked to male sex, older age and a more affluent social class. At the population level, the contribution of unrecorded alcohol to overall consumption varied widely across countries. Few countries confirmed the traditional picture of a relatively small proportion of unrecorded alcohol in high-income countries (Spain and Poland). However, the majority of countries showed substantial amounts of unrecorded consumption, albeit to varying degrees based on different assumptions. Unfortunately, we have no way to determine which assumptions are most realistic. However, the overall level of unrecorded consumption was higher than traditionally assumed or reported by European high-income countries.

\section{Limitations}

When discussing levels and proportions of unrecorded consumption, we need to take into consideration several limitations. First, the psychometric properties were not measured in the RARHA SEAS survey in individual countries. However, key items were selected by experts from 21 countries who based their assessment on literature reviews and findings from previous studies. Specifically, heterogeneity in survey questions between different countries renders comparability between them problematic. Second, only a portion of unrecorded consumption was assessed in the survey, and some forms of illegal alcohol (such as industrial counterfeit) as well as surrogate alcohol were omitted. This is worthwhile noting as a potential source of underestimation, especially given that surrogate alcohol consumption was previously identified by ministerial officials of some countries as being problematic (for an overview see [5]; online suppl. Table 3). Surrogate alcohol includes medicinal or industrial alcohol which is consumed as beverage alcohol and is more prevalent among people with alcohol use 
disorders of lower socioeconomic status [22-24]. While consumption of surrogate alcohol may only be seen in marginalized populations and thus may be underestimated by general population surveys, it still contributes to unrecorded consumption. Further, industrially produced contraband and counterfeit alcohol were not assessed, even though in some countries these types of unrecorded alcohol are distributed within legal distribution networks $[25,26]$. While the contribution of this category has been estimated to be substantial in some European countries, the methodology remains unclear [25]. Further, as respondents may not be aware of the unrecorded status of counterfeit alcohol sold in shops and bars, general population surveys may result in underestimations of this category, as well.

Third, the degree to which acquisition can be used as a proxy for personal consumption is debatable. For example, for $7 \%$ of all survey respondents, the total of unrecorded acquisitions over the year exceeded the overall volume of all alcohol reported as consumed. This may indicate that unrecorded alcohol was not bought for consumption, or at least not for personal consumption. Of note, people acquiring unrecorded alcohol were often people from a more affluent social class, who may have brought alcohol back from their travels. Thus, there might be an interaction of wealth and the category of unrecorded alcohol, which should be examined in future studies. In particular, future analyses should investigate if people from a more affluent social class tend to acquire both home-made alcohol and alcohol from cross-border shopping. On the other hand, higher volumes of unrecorded alcohol than total consumption volumes may simply indicate that the current consumption questions underestimate real consumption for a number of reasons, such as sampling frame [27], non-response bias [28], or social desirability biases [29]. The latter bias may play less of a role for questions on acquisition than for questions on consumption.

\section{Interpretation of Results}

In any case, the current questionnaire does not allow for an unequivocal interpretation of results. Inconsistencies of responses to alcohol surveys are not unusual. For instance, it is common to find respondents declaring themselves to be abstainers for the past year who subsequently fill in a frequency of drinking larger than 0 . Inconsistencies apply even to seemingly clear concepts such as lifetime abstention. In a follow-up study of the National Alcohol Survey of the US in 1992, over half of respondents who reported never having had any kind of alco- holic beverage over their lifetime had in fact reported drinking in earlier surveys [30]. In other words, answers to alcohol surveys seem to be quickly composed by respondents without too much thought given to the consistency of answers (generally: [31]). While psychometric properties of the overall alcohol consumption module of the SEAS questionnaire are not available, the results reiterate that per capita consumption is generally underestimated if based on survey data alone. We highlight that survey data should be interpreted in light of their psychometric properties - if available. In a separate manuscript currently in preparation, coverage of per capita consumption using SEAS data will be estimated, which will contribute to validating the SEAS questionnaire.

Despite the limitations and irrespective of the interpretation of the results, the current study clearly shows that unrecorded alcohol plays a role in modern high-income countries in Europe. For Greece, the comparative risk assessment for alcohol for the year 2000 estimated $2 \mathrm{~L}$ of pure alcohol per capita, corresponding to $17.6 \%$ of total consumption [32]. This is clearly much lower than the RARHA SEAS estimate of $4.0 \mathrm{~L}$ per capita, or two-thirds of total consumption. The reasons for the increase in unrecorded alcohol can probably be found in the country's economic crisis, which also led to a shrinking of the health-care system and worsening of key health indicators, such as mortality [33]. The level of total alcohol consumption remained stable [1], albeit with a shift from recorded to unrecorded alcohol, as the latter is cheaper [16]. This is in line with a general shift to the shadow economy for many goods during the crisis [34].

At the opposite end of the spectrum, Spain showed almost no unrecorded alcohol according to the respondents of this survey (Tables 2, 3). This is surprising as Spain is a major wine producer, and about $20 \%$ of all alcohol consumed in the country is in the form of wine [1]. These findings would suggest that all the wine produced in Spain is fully registered and that no sales of unregistered wine take place, and no wine producers consume their own product or offer unregistered wine to friends and family. While there is no specific alcohol excise tax on wine [1], and thus no disincentive to register it, there should still be some investigation on the use or sale of unrecorded wine in Spain. Based on estimates of the Food and Agriculture Organization by the UN (taken from the Global Information System on Alcohol and Health [35]), one would expect a higher wine production, which may indicate the existence of some unrecorded wine, for a total of about $2 \mathrm{~L}$ pure alcohol per capita. As for Poland, unrecorded alcohol confirmed in the survey does not re- 
flect the total volume as a large proportion of unrecorded supply is sold within legal distribution channels and therefore, the consumers are not aware of the illicit status of the alcohol they purchase $[26,36,37]$.

\section{Implications of Unrecorded Alcohol Use}

The findings illustrate that unrecorded alcohol is common in several European countries, albeit there are considerable differences with regard to the type of unrecorded alcohol and the group of persons most involved in the acquisition of unrecorded alcohol, especially with regards to social class. The most consistent finding across all countries, however, is that heavier drinkers were more likely to come into contact with unrecorded alcohol. As there are some specific risks related to specific kinds of unrecorded alcohol $[5,38]$ and because unrecorded alcohol is often very affordable and widely available for persons with alcohol use disorders [7], this topic should find its way into clinical work, building upon the epidemiological evidence gathered to date. To start with, a solid assessment of unrecorded alcohol use, adaptive to different contexts, is required (see also next section). In the long run, well-established instruments to capture alcohol consumption and problems, such as the "Alcohol Use Disorder Identification Test," may be extended with questions on unrecorded alcohol use, which may prompt clinicians to consider talking about unrecorded alcohol with their patients.

More widespread recognition of unrecorded alcohol use may further deepen our understanding of its public health implications. Currently, the alcohol-attributable disease burden is estimated based on survey data not accounting for unrecorded consumption (see e.g., [1]). Inclusion of unrecorded alcohol items in general population surveys may change our understanding how unrecorded consumption is distributed among drinkers, and may consequently alter the estimates of alcohol-attributable burden.

\section{Unrecorded Monitoring: Consistent Assessment Required}

Given the contribution of unrecorded alcohol in European high-income countries, unrecorded alcohol consumption should be included in the usual monitoring and surveillance systems for risk factors for non-communicable disease $[39,40]$. Since alcohol is also an important risk factor for injury and communicable disease [41], there is even more reason for systematic monitoring.

In order to avoid inconsistencies between and within surveys, we recommend using the WHO STEP wise Ap-

Unrecorded Alcohol in Seven EU

Countries proach to Surveillance for future monitoring [42]. In this questionnaire, after establishing the level of alcohol consumption over a specified period of time (for WHO STEPS, this time period is 1 week), a further question asks for the types of unrecorded alcohol consumed and their potential part overall in consumption volumes reported (online suppl. Material). This technique allows us to arrive at the proportion of unrecorded alcohol for a specific period of time, which can then be easily extrapolated for monitoring purposes. Please note that overall, depending on the number of unrecorded categories of alcohol for a country, up to 6 short questions are required, and for the majority of the people - who have no any unrecorded alcohol consumption to report - one question is sufficient.

\section{Conclusion}

This study highlights that unrecorded alcohol is not necessarily linked to a lower socioeconomic status and that unrecorded alcohol substantially contributes to total consumption in several high-income countries in Europe. A standardized assessment adaptable to locally relevant categories of unrecorded alcohol is required to overcome conceptual discrepancies and implausible variations of estimates. In our view, the WHO STEPS survey module meets these requirements and should be considered in future alcohol surveys, providing the base for a continuous monitoring of unrecorded alcohol consumption in Europe and elsewhere.

\section{Acknowledgment}

We want to acknowledge Zsuzsanna Elekes for providing data on the proportion of acquired alcohol drunk by Hungarian respondents to SEAS. Further, we thank Anastasios Fotiou and Ljiljana Muslić for providing English translations of the Greek and Croatian unrecorded modules respectively.

\section{Statement of Ethics}

The RARHA SEAS survey was conducted without prior approval by Ethics Committees as surveys are generally exempted from undergoing ethical review in the participating countries including Poland, which was the RARHA SEAS study center.

\section{Disclosure Statement}

The authors have no conflicts of interest to declare. 


\section{Funding Sources}

This article was produced under the DEEP SEAS service contract (Developing and Extending Evidence and Practice from the Standard European Alcohol Survey - www.deep-seas.eu). The DEEP SEAS project has been funded by the EU Health Programme 2014-2020 under a service contract 20177124 with the Consumers, Health, Agriculture and Food Executive Agency (Chafea) acting under the mandate from the European Commission, from December 18, 2018 to December 17, 2021. Disclaimer: Views expressed in this article are those of the authors only, and do not necessarily reflect the views of the European Commission Health Programme or Chafea. J.R. acknowledges funding from the Canadian Institutes of Health Research, Institute of Neuro- sciences, Mental Health and Addiction (Canadian Research Initiative in Substance Misuse Ontario Node grant number SMN13950).

\section{Author Contributions}

J.R. and J. Manthey conceptualized the article and wrote a first draft. J. Manthey did most of the statistical analyses, with contributions from C.K. and C.P. J. Moskalewicz and J.S. conceptualized the survey and cleaned the data; they also wrote a first draft of the methods section. All authors commented on various versions of the article, helped with the interpretation of the results, and approved of the final version.

\section{References}

1 World Health Organization. Global status report on alcohol and health 2018. Geneva: WHO Press; 2018.

2 Rehm J, Mathers C, Popova S, Thavorncharoensap M, Teerawattananon Y, Patra J. Global burden of disease and injury and economic cost attributable to alcohol use and alcoholuse disorders. Lancet. 2009 Jun;373(9682): 2223-33.

3 Alcohol consumption (indicator) [Internet]. [cited 10 September 2019], 2019.

4 Lachenmeier DW, Gmel G, Rehm J. Unrecorded alcohol consumption. In: Boyle $\mathrm{P}$, Boffetta P, Lowenfels AB, Burns H, Brawley O, Zatonski W, et al., editors. Alcohol: Science, Policy, and Public Health. Oxford: Oxford University Press; 2013. pp. 132-42.

5 Rehm J, Kailasapillai S, Larsen E, Rehm MX, Samokhvalov AV, Shield KD, et al. A systematic review of the epidemiology of unrecorded alcohol consumption and the chemical composition of unrecorded alcohol. Addiction. 2014 Jun;109(6):880-93.

6 Manthey J, Shield K, Rylett M, Hasan OSM, Probst C, Rehm J. Global alcohol exposure between 1990 and 2017 and forecasts until 2030: a modelling study. Lancet. 2019 Jun; 393(10190):2493-502.

7 Neufeld M, Wittchen HU, Ross LE, FerreiraBorges C, Rehm J. Perception of alcohol policies by consumers of unrecorded alcohol - an exploratory qualitative interview study with patients of alcohol treatment facilities in Russia. Subst Abuse Treat Prev Policy. 2019 Nov; 14(1):53.

8 Rehm J, Larsen E, Lewis-Laietmark C, Gheorghe P, Poznyak V, Rekve D, et al. Estimation of unrecorded alcohol consumption in low-, middle-, and high-income economies for 2010. Alcohol Clin Exp Res. 2016 Jun;40(6): 1283-9.

9 Probst C, Manthey J, Merey A, Rylett M, Rehm J. Unrecorded alcohol use: a global modelling study based on nominal group as- sessments and survey data. Addiction. 2018 Jul;113(7):1231-41.

10 Rehm J, Poznyak V. On monitoring unrecorded alcohol consumption. Alcoholism and Drug Addiction. 2015;28(2):79-89.

11 World Health Organization. STEPwise approach to surveillance (STEPS). 2019. [Accessed January 22, 2019]. Available from: http://www.who.int/chp/steps/en/.

12 World Health Organization. STEPS: A framework for surveillance. The WHO STEPwise approach to Surveillance of noncommunicable diseases. 2003. [Accessed March 29, 2019]. Available from: https://www.who.int/ncd surveillance/en/steps_framework_dec03.pdf.

13 Andréasson S, Nilsson T, Bränström R. Monitoring Alcohol and Alcohol Related Problems in Sweden. Contemp Drug Probl. 2009; 36(3-4):625-42.

14 Otto E, Martens K, Lepane L, Josing M, Reiman M, Hansa A. Alcohol market, consumption and harms in Estonia. Tallinn: Estonian Institute of Economic Research; 2018.

15 Säkkinen S, Borodulin K, Heino A, Häkkinen $\mathrm{P}$, Kovanen L, Puhakka T, et al. Päihdetilastollinen vuosikirja 2018: Alkoholi ja huumeet. Helsinki: Terveyden ja hyvinvoinnin laitos; 2018. Available from: http://urn.fi/URN: ISBN:978-952-343-251-2.

16 Leifman H. Estimations of unrecorded alcohol consumption levels and trends in $14 \mathrm{Eu}-$ ropean countries. Nordisk Alkohol Nark. 2001;18 1_suppl:54-70.

17 Reducing Alcohol Related Harm (RARHA). Comparative monitoring of alcohol epidemiology across the EU: Baseline assessment and suggestions for future action. Synthesis report. 2016. [Accessed March 28, 2019. Available from: http://www.rarha.eu/NewsEvents/ LatestNews/Lists/LatestNews/Attachments/36/Comparative\%20monitoring\%20 \%20of\%20alcohol\%20epidemiology\%20\%20 across $\% 20$ the $\% 20 \mathrm{EU} \% 20 \% \mathrm{E} 2 \% 80 \% 93 \% 20$ 27.02.pdf.
18 Rehm J, Klotsche J, Patra J. Comparative quantification of alcohol exposure as risk factor for global burden of disease. Int J Methods Psychiatr Res. 2007;16(2):66-76.

19 Midanik LT. Validity of self-reported alcohol use: a literature review and assessment. $\mathrm{Br} \mathrm{J}$ Addict. 1988 Sep;83(9):1019-30.

20 Poznyak V, Fleischmann A, Rekve D, Rylett M, Rehm J, Gmel G. The world health organization's global monitoring system on alcohol and health. Alcohol Res. 2013;35(2):244-9.

21 R Core Team. A language and environment for statistical computing. R Foundation for Statistical Computing. Vienna, Austria: R Foundation for Statistical Computing; 2018. [updated December 18, 2018]. Available from: https:// www.R-project.org/.

22 Lachenmeier DW, Rehm J, Gmel G. Surrogate alcohol: what do we know and where do we go? Alcohol Clin Exp Res. 2007 Oct;31(10): 1613-24.

23 Neufeld M, Wittchen HU, Rehm J. Drinking patterns and harm of unrecorded alcohol in Russia: a qualitative interview study. Addict Res Theory. 2017;25(4):310-7.

24 Razvodovsky YE. Consumption of noncommercial alcohol among alcohol-dependent patients. Psychiatry J. 2013;2013:691050.

25 International Alliance for Responsible Drinking (IARD). Alcohol in the Shadow Economy: Unregulated, Untaxed, and Potentially Toxic. 2018. [April 03, 2019]. Available from: http:// www.iard.org/wp-content/uploads/2018/06/ Alcohol-in-the-Shadow-Economy.pdf.

26 Moskalewicz J, Österberg E. Changes in alcohol affordability and availability: Twenty years of transitions in Eastern Europe. Helsinki: National Institute for Health and Welfare; 2016. [cited May 03, 2019].

27 Shield KD, Rehm J. Difficulties with telephone-based surveys on alcohol consumption in high-income countries: the Canadian example. Int J Methods Psychiatr Res. 2012 Mar;21(1):17-28. 
28 Nugawela MD, Langley T, Szatkowski L, Lewis S. Measuring Alcohol Consumption in Population Surveys: A Review of International Guidelines and Comparison with Surveys in England. Alcohol Alcohol. 2016 Jan;51(1):84-92.

29 Davis CG, Thake J, Vilhena N. Social desirability biases in self-reported alcohol consumption and harms. Addict Behav. 2010 Apr;35(4):302-11.

30 Rehm J, Irving H, Ye Y, Kerr WC, Bond J, Greenfield TK. Are lifetime abstainers the best control group in alcohol epidemiology? On the stability and validity of reported lifetime abstention. Am J Epidemiol. 2008 Oct;168(8):866-71.

31 Kahneman D. Thinking Fast and Slow. New York: Farrar, Straus and Giroux; 2011.

32 Rehm J, Room R, Monteiro M, Gmel G, Graham K, Rehn T. Comparative quantification of health risks; Global and regional burden of disease attributable to selected major risk factors. Volume 1. Geneva: World Health Organization; 2004. pp. 959-1108.

33 Tyrovolas S, Kassebaum NJ, Stergachis A, Abraha HN, Alla F, Androudi S, et al.; Global
Burden of Disease 2016 Greece Collaborators. The burden of disease in Greece, health loss, risk factors, and health financing, 2000-16: an analysis of the Global Burden of Disease Study 2016. Lancet Public Health. 2018 Aug;3(8):e395-406.

34 Bitzenis A, Vlachos V, Schneider F. An Exploration of the Greek Shadow Economy: Can Its Transfer into the Official Economy Provide Economic Relief Amid the Crisis? J Econ Issues. 2016;50(1):165-96.

35 World Health Organization. Global Information System on Alcohol and Health (GISAH). 2018. [Accessed February 13, 2019]. Available from: https://www.who.int/gho/alcohol/en/.

36 Lachenmeier DW, Ganss S, Rychlak B, Rehm J, Sulkowska U, Skiba M, et al. Association between quality of cheap and unrecorded alcohol products and public health consequences in Poland. Alcohol Clin Exp Res. 2009 Oct; 33(10):1757-69.

37 Moskalewicz J, Simpura J. The supply of alcoholic beverages in transitional conditions: the case of Central and Eastern Europe. Addiction. 2000 Dec;95(Suppl 4):S505-22.
38 Lachenmeier DW, Rehm J. Unrecorded alcohol: a threat to public health? Addiction. 2009 Jun;104(6):875-7.

39 World Health Organization. Integrated surveillance of Noncommunicable diseases (iNCD). 2015. [Accessed March 29, 2019]. Available from: http://ec.europa.eu/health/ indicators/docs/incd_en.pdf.

40 Mikkelsen B, Williams J, Rakovac I, Wickramasinghe K, Hennis A, Shin HR, et al. Life course approach to prevention and control of non-communicable diseases. BMJ. 2019 Jan; 364:1257.

41 Rehm J, Gmel GE Sr, Gmel G, Hasan OS, Imtiaz S, Popova S, et al. The relationship between different dimensions of alcohol use and the burden of disease-an update. Addiction. 2017 Jun;112(6):968-1001.

42 World Health Organization. WHO STEPS Instrument (Core and Expanded). 2015. [Accessed March 29, 2019]. Available from: https://www.who.int/ncds/surveillance/ steps/instrument/STEPS_Instrument V3.2.pdf. 